World Applied Sciences Journal 3 (1): 122-131, 2008

ISSN 1818-4952

(C) IDOSI Publications, 2008

\title{
Determining the Specific Ground Conductivity Aided by the Horizontal Electric Dipole Antenna Near the Ground Surface
}

\author{
${ }^{1,2}$ Seyed Vahab-ALdin Makki and ${ }^{1}$ Tohid Zargar Ershadi \\ ${ }^{1}$ Faculty of Electrical, Khaje Nasir Toosi University, Tehran, Iran \\ ${ }^{2}$ Faculty of Engineering, Razi University, Kermanshah, Iran
}

\begin{abstract}
The ground conductivity is the most important factor in the transmitter's coverage area in ground wave propagation. Regarding the day-to-day increase in digital broadcasting, a lower sensitivity of this kind of broadcasting and ability to create single frequency networks, it seems necessary to increase the accuracy of ground conductivity to minimize fading zones. The higher the above-mentioned conductivity, the lower the ground wave attenuation. Also in this case, the transmitted wave will tilt less towards the ground to satisfy the boundary conditions in electric conductivity and so-called will enter the earth. In most of the presented papers to determine the field strength, conductivity is considered as known, but it's dependent upon the soil genus, the annual/monsoon precipitation and the heat average. Here it is intended to provide a new method based on Mie algorithm to determine the conductivity based on the difference of horizontal electric dipole near the ground. The previous conductivity measurements included determining it in a point by point manner in a low frequency and determining the conductivity based on the coverage area intensity. The new method holds the two methods advantages together.
\end{abstract}

Key words: Ground conductivity . horizontal electric dipole . Mie method . impedance antenna . MW transmitter coverage

\section{INTRODUCTION}

Determining the transmitter's Field Strength (FS) is influenced by Ground Conductivity (GC) especially in Medium Wave $(\mathrm{FS}>60 \quad d B \mu V / M) \quad[1]$. In the aforementioned band and regarding the related recommendations [2] the $\mathrm{GC}$ is defined in 9 intervals (Table 1).

The conductivity and permittivity effect on the environment's propagation constant_ which itself determines the field structure and propagation path attenuation_ is in a way that conductivity is the most dependent. For example in the Fig. 1 the propagation constant (K2) has been drawn in three frequencies $0.5,1$ and $1.5 \mathrm{MHz}$ based on the permittivity (up) and conductivity (down). It is obvious that the propagation constant is not sensitive to permittivity changes, but fully dependent on conductivity.

The related permittivity is considered regarding previous figures and after determining the GC. The simulated electric field by FDTD is drawn in Fig. 2. The tilting effect of electric field is observed in the common surface.

The FS of the short monopole antenna introduced by ITU [3] in the Fig. 3 can be observed in $1 \mathrm{MHz}$ based on distance. Considering the Fig. 3, one degree
Table 1: Standard values and ranges of GC

\begin{tabular}{lcl}
\hline Limiting values of the range $(\mathrm{S} / \mathrm{M})$ & $\begin{array}{l}\text { Standard } \\
\text { values } \\
(\mathrm{S} / \mathrm{M})\end{array}$ \\
\hline 5 & Lower limit & 3 \\
$3 \mathrm{e}-2$ & 7 & $1.7 \mathrm{e}-2$ \\
$1 \mathrm{e}-2$ & $5.5 \mathrm{e}-2$ & $5.5 \mathrm{e}-3$ \\
$3 \mathrm{e}-3$ & $1.7 \mathrm{e}-2$ & $1.7 \mathrm{e}-3$ \\
$1 \mathrm{e}-3$ & $5.5 \mathrm{e}-3$ & $5.5 \mathrm{e}-4$ \\
$3 \mathrm{e}-4$ & $1.7 \mathrm{e}-3$ & $1.7 \mathrm{e}-4$ \\
$1 \mathrm{e}-4$ & $5.5 \mathrm{e}-4$ & $5.5 \mathrm{e}-5$ \\
$3 \mathrm{e}-5$ & $1.7 \mathrm{e}-4$ & $1.7 \mathrm{e}-5$ \\
$1 \mathrm{e}-5$ & $5.5 \mathrm{e}-5$ & $5.5 \mathrm{e}-6$ \\
\hline
\end{tabular}

increase between $20-100 K M$ in $\mathrm{GC}$ is equal to a somehow increase of $8-10 \mathrm{~dB}$ in the transmitter power.

Determining electric field: Zenneck was the first to do a study on determining the ground wave FS [4]. Zenneck's hypothesis was the flattening of the phase plane in a reference as a source and vertical on the interface. He was also the first to measure the wave tilt. In the Fig. 4 the wave tilt angle towards the ground has been drawn based on frequency of different conductivities. 

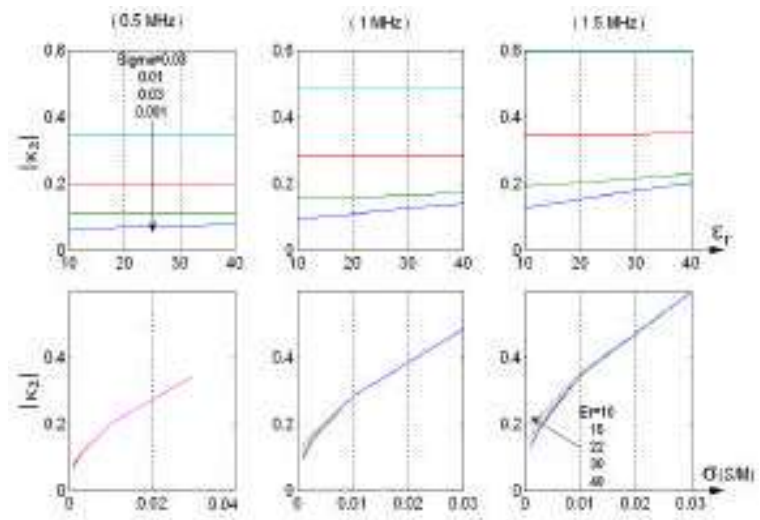

Fig. 1: Propagation constant vs. permittivity (up) and $\mathrm{GC}$ (down)

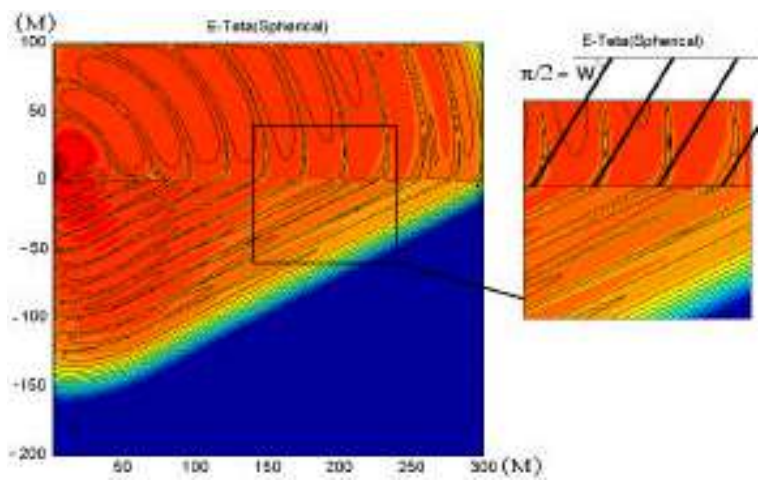

Fig. 2: FS of antenna and tilt effect on the interface

Sommerfeld provided an answer for electric field obtained from a current element in 1907 in which to determine the electric field the solution to the integral below should be obtained [5].

$$
\begin{aligned}
& \mathrm{E}_{0 \mathrm{r}}=\frac{\partial^{2} \mathrm{U}_{0}}{\partial \mathrm{z} \partial \mathrm{r}} \\
& \mathrm{E}_{0 \mathrm{z}}=\left(\mathrm{k}^{2}+\frac{\partial^{2}}{\partial \mathrm{z}^{2}}\right) \mathrm{U}_{0} \\
& \mathrm{H}_{\varphi}=\dot{\mathrm{\varepsilon}}_{0} \omega \frac{\partial \mathrm{U}_{0}}{\partial \mathrm{r}} \\
& \mathrm{U}_{0}=\frac{\mathrm{Idl}}{\left(4 \pi \mathrm{j} \varepsilon_{0} \omega\right)} \int_{0}^{\infty} \frac{\mathrm{e}^{\left(-\mathrm{u}_{0}|\mathrm{z}-\mathrm{h}|\right)}+\mathrm{R}_{\mathrm{e}}(\mathrm{g}) \mathrm{e}^{\left(-\mathrm{u}_{0}|\mathrm{z}+\mathrm{h}|\right)}}{\mathrm{u}_{0}} \mathrm{~J}_{0}(\mathrm{gr}) \mathrm{gdg} \\
& \mathrm{u}_{0}=\sqrt{\mathrm{g}^{2}+\gamma_{0}^{2}}, \quad \mathrm{u}=\sqrt{\mathrm{g}^{2}+\gamma^{2}} \\
& \gamma_{0}=\mathrm{j} \omega \sqrt{\varepsilon_{0} \mu_{0}}, \quad \gamma_{0}=\sqrt{\mathrm{j} \omega \mu_{0}\left(\sigma+\mathrm{j} \varepsilon_{\mathrm{r}} \varepsilon_{0} \omega\right)} \\
& \mathrm{K}_{0}=\frac{\mathrm{u}_{0}}{\left(\mathrm{j} \varepsilon_{0} \omega\right)}, \quad \mathrm{K}=\frac{\mathrm{u}}{\left(\sigma+\mathrm{j} \varepsilon_{\mathrm{r}} \varepsilon_{0} \omega\right)} \\
& \mathrm{R}_{\mathrm{e}}(\mathrm{g})=\left(\mathrm{K}{ }_{0}-\mathrm{K}\right) /\left(\mathrm{K}_{0}+\mathrm{K}\right)
\end{aligned}
$$

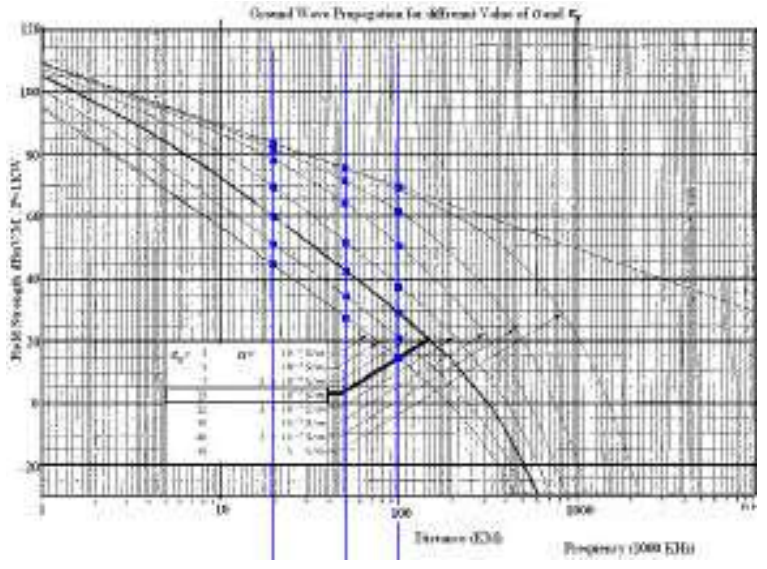

Fig. 3: FS of $1 \mathrm{KW}$ short monopole vs. distance in different $\mathrm{GC}$

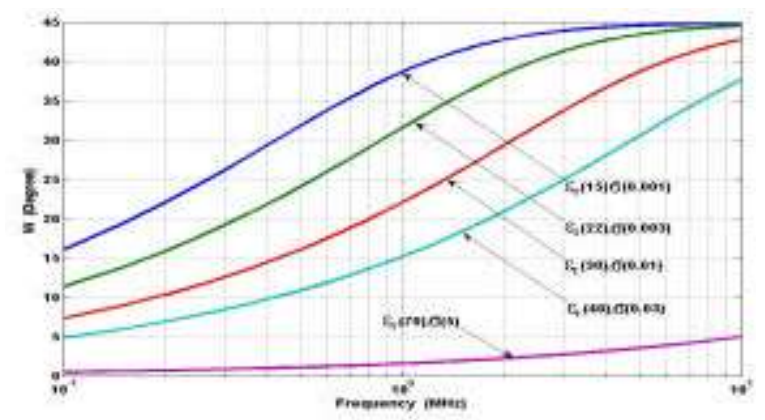

Fig. 4: Tilt angle vs. frequency

K.A. Norton later in 1936 and 1937 provided a relatively simple approximation to what was considered later as the approximate solution to the aforementioned integral. Today in most cases this method is used [6]. The above mentioned approximation is used for flat earth which is considered as a coefficient to extra degradation in distances more than $70 \mathrm{~km}$. J. R. Wait provided a solution for this integral in 1953 which led to figuring out the error function by complex argument [7]. R.W.P. King presented a method to solve the integral in 1969 and 1998 which led to the determination of Fresnel functions [8]. It should be noted that King solved the problem in two cases of flat earth and spherical earth. Of course King relations are more accurate in high frequencies $(f \geq 3 \mathrm{MHz})$ and high GC $(\sigma>0.03 S / M)$. R.E. Collin proposed a method in 2004 in which solution of the integral led to computation of error function by complex argument [9]. In this method the earth is also considered flat. Fig. 5 demonstrate these three methods in case of short vertical antenna on earth of characteristics $(\varepsilon=30$, $\sigma=0.01 \mathrm{~S} / \mathrm{M})$ in $\mathrm{f}=1 \mathrm{MHz}$. 


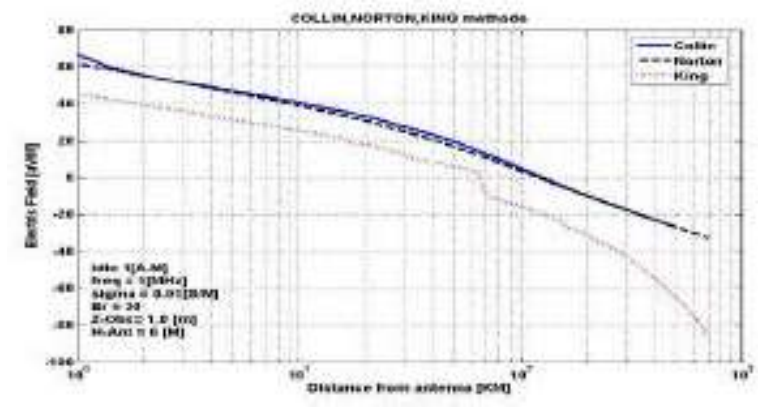

Fig. 5: FS of current element in Collin, Norton and King method

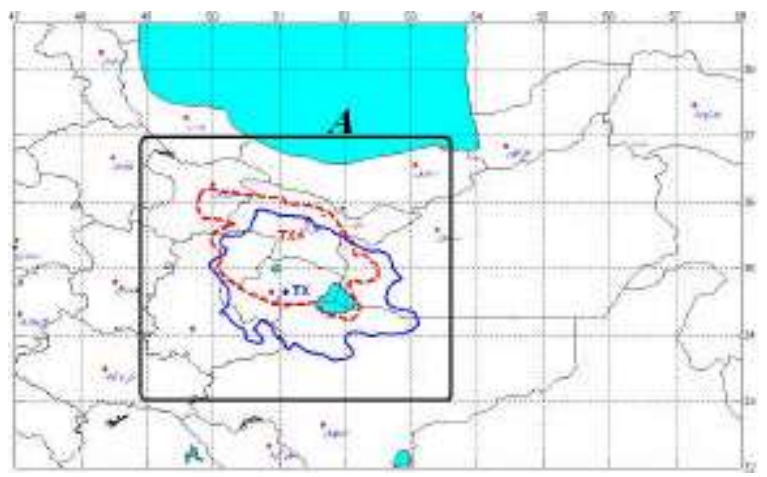

Fig. 6: Different between coverage of the same transmitter in two points

It is observed that Collin's and Norton's methods are too close, but there is no sign of earth curve after $100 \mathrm{~km}$ in King's method the earth curve can be observed, but the electric field measure is less than the previous two methods due to the King's definition of relation in $f=1-30 \mathrm{MHz}$. The fracture effect is due to the change of flat earth to spherical earth. In the above mentioned methods the observation point is distant from the antenna, e.g. Collin has used this approximation.

$$
\mathrm{H}_{0}^{1}(\mathrm{kr}) \approx \sqrt{\frac{2}{\pi \mathrm{kr}}} \mathrm{e}^{\left(\mathrm{jk}-\frac{\pi}{4}\right)}
$$

In which the Henkel function holds the first place for great argument approximation, but to determine antenna impedance it is necessary to compute the FS near antenna together with earth effect which is not possible in this method. Here Mie method is used to determine the FS near antenna_ which is the base to compute antenna impedance _ and Sommerfeld's integral is not involved.

Accurately determining the $\mathrm{GC}$ by the use of correctly locating the transmitter's position has an

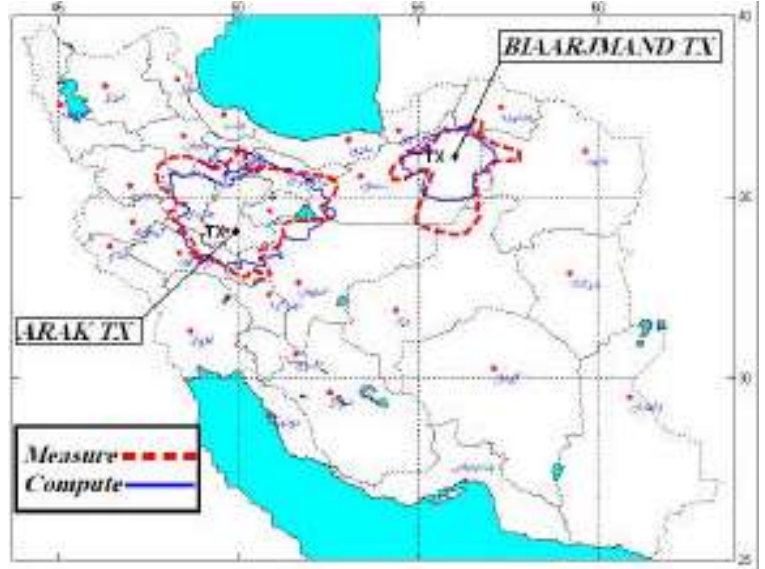

Fig. 7: Coverage area (Measure and Compute) of Arak and Biaarjmand

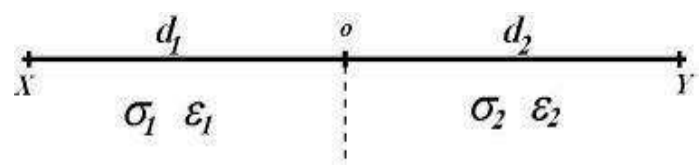

Fig. 8: Propagation path with changing $\mathrm{GC}$ in $\mathrm{O}$

effective effect on increasing the coverage area of the transmitter. For example, if there are two similar (+) transmitters in area A, one (---) near the northern mountains and the other $(-)$ in distance of $150 \mathrm{kM}$ from the previous transmitter, the two transmitters' difference of coverage area is $4.51 \%$ which includes an area of $9025 \mathrm{kM}^{2}$ of the southern areas. The mountains of the northern area are the reason to the phenomenon; they will cause the field's contours compress (Fig. 6).

The only reference to GC is the ITU-R P 832-1 [2]. For example, coverage and measurement computation is considered for the transmitters in the desert border. The difference of measurement and computation by the use of the related atlas of the two transmitters in northeastern (Biaarjomand) and center (Arak) of Iran can be observed in Fig. 7.

The difference of measurement and computation in plateaus areas (the almost congenial areas) has been the highest and the reason has been the true difference of the conductivity and the conductivity in the related atlas. The high attenuation due to the two step variation of the GC in mountainous areas is the reason to the congenial converges in the mountainous areas (north) not accuracy in determining GC.

Millington proposed a method to determine FS in uncongenial areas [10] which is based on the staircase variation of GC in propagation path. The FS in $Y$ point in the Fig. 8 resulting from the transmitter in the $X$ point is defined as per the below relations. 
Table 2: Sirjaan plateau conductivity

\begin{tabular}{|c|c|c|c|c|}
\hline Dip/Distance of probe (M) & $0.2 / 4 \quad 0.3 / 6$ & $0.3 / 6$ & $0.3 / 6$ & $0.3 / 6$ \\
\hline $\mathrm{s}(\mathrm{mS} / \mathrm{M})$ & 3.87 & 7.37 & 6.93 & 8.19 \\
\hline \multicolumn{5}{|c|}{ Table 3: Maahidasht plateau conductivity } \\
\hline \multirow{3}{*}{$\begin{array}{l}\text { Dip/distance } \\
\text { of probs (M) }\end{array}$} & $0.1 / 2$ & $0.1 / 2$ & & $0.1 / 2$ \\
\hline & $0.2 / 4$ & $0.2 / 4$ & & $0.2 / 4$ \\
\hline & $0.3 / 6$ & $0.3 / 6$ & & $0.3 / 6$ \\
\hline \multirow[t]{3}{*}{$\overline{\mathrm{s}(\mathrm{mS} / \mathrm{M})}$} & 25.84 & 15.16 & & 20.1 \\
\hline & 40.19 & 33.44 & & 36.84 \\
\hline & 44.21 & 45.73 & & 45.73 \\
\hline
\end{tabular}

Table 4: Kermanshah plateau conductivity

\begin{tabular}{lccc}
\hline Dip/Distance & $0.1 / 2$ & $0.1 / 2$ & $0.1 / 2$ \\
of probs (M) & $0.2 / 4$ & $0.2 / 4$ & $0.2 / 4$ \\
& $0.3 / 6$ & & \\
\hline $\mathrm{s}(\mathrm{mS} / \mathrm{M})$ & 31.207 & 6.49 & 3.014 \\
& 76.517 & 8.921 & 1.878 \\
& 106.103 & & \\
\hline
\end{tabular}

$$
\begin{aligned}
& E_{Y X}=E_{2}\left(d_{1}+d_{2}\right)+E_{1}\left(d_{1}\right)-E_{2}\left(d_{1}\right) \\
& E_{Y}=0.5\left(E_{Y X}+E_{X Y}\right)
\end{aligned}
$$

In this method, $E n(d n)$ is the field from the $d n$ on a surface with $n$ characteristics, computable or based on the curves of $\mathrm{P}$ 368-7 recommendations [3].

The $E 1(d 1)-E 2(d 1)$ value based on $\sigma 2<\sigma 1$ or $\sigma 2>\sigma l$ is known as Sea Gain (SG) or Land Loss (LL). In $\mathrm{GC}$ atlas one can find paths with quick conductivity and multi step variation, but for sure the variation is constant and through several kilometers. If a $\mathrm{GC}$ variation in a distance from $30 \mathrm{kM}$ varies 3 levels, the difference of FS in conductivity variations will be constant and as follows in the staircase (Fig. 10).

GC increase (improvement) in an area which has no accurate map and tables can cause increase (or creation) in extra coverage area For example existence of an area which hasn't been in Iran's GC atlas has caused a coverage area behind the mountains between the transmitter and the coverage area (Fig. 11) [11].

\section{Methods to measure earth conductivity}

Measuring earth receptivity: The direct measurement of earth resistivity is the first method to measure conductivity [12]. One can mention the following points as the disadvantages of the above method in measuring GC: (A)-Attention is not paid to frequency and its effect.(B)-It cannot analyze parameters like rough earth. If the aforementioned method is used, there will be a need for modification of relations and making

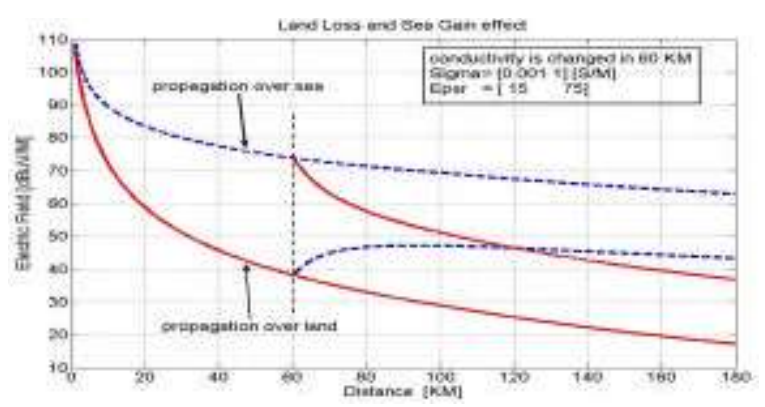

Fig. 9: FS over Sea or Land and changing media in 60 $\mathrm{KM}$

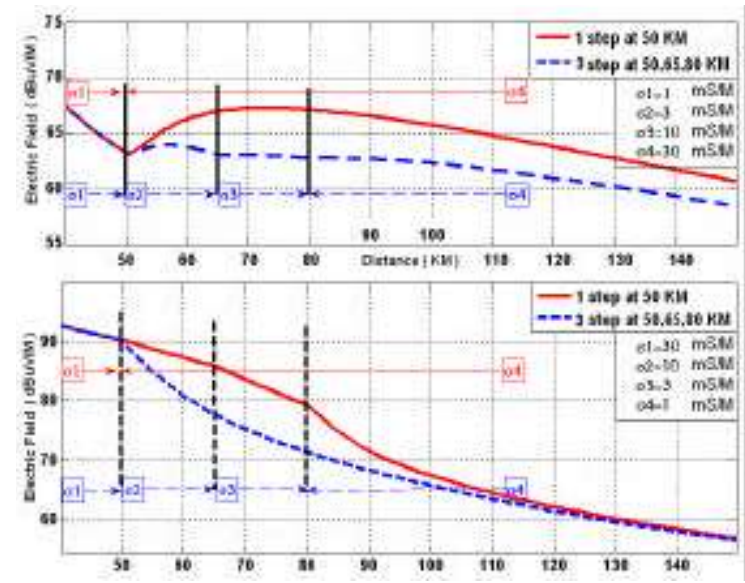

Fig. 10: $\mathrm{FS}(\mathrm{dBuV} / \mathrm{M})$ vs. distance for changing the $\mathrm{GC}(1-30 \mathrm{mS} / \mathrm{M})$

them dependent on frequency. Table 2 shows Sirjaan plateau conductivity with the defined value $s=$ $m S / M)$ in $29^{\circ} 30-34^{\prime}$ latitude and ${ }^{\circ} 43-51^{\prime}$ longitude, Table 3 shows Maahidasht plateau conductivity with the $(s=m S / M)$ defined value in ${ }^{\circ} 8-15^{\prime}$ latitude and $46^{\circ}$ 1-57' longitude and Table 4 shows Kermanshah plateau conductivity with $(s=m S / M)$ defined value in $34^{\circ} 23-28^{\prime}$ latitude and $47^{\circ} 0-10^{\prime}$ longitude (it should be mentioned that in Table 4 , the measurement points head the mountains from plateau which causes decrease in conductivity).

It is realized from tables that GC varies in different depths leading to the point that the method needs modification.

Measuring conductivity based on FS: The next methods do not have the previous shortcomings, but is relatively long, vast and dependent upon transmitter's frequency (variation of which was not a much easy task). The points around a transmitter in transmitting defined circumstances based on measuring FS, production of an information bank of FS and optimized 


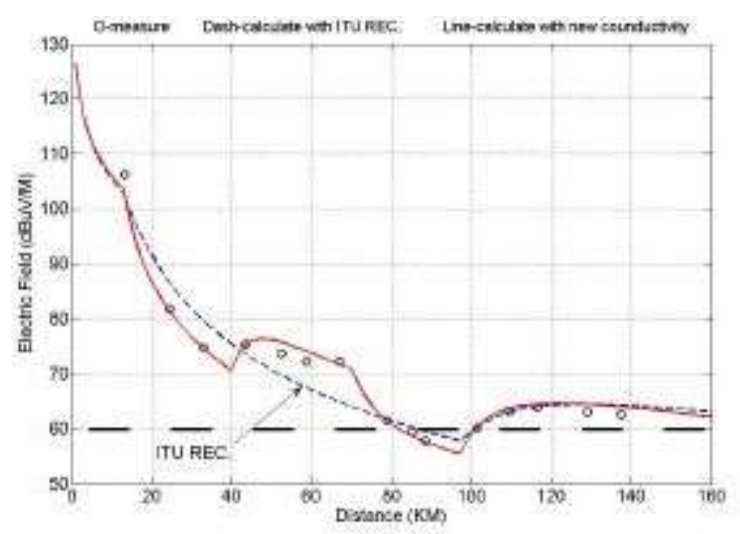

Fig. 11: Meas. (o), Compute with ITU Rec. (-) and compute with modification value for Rec. (-)

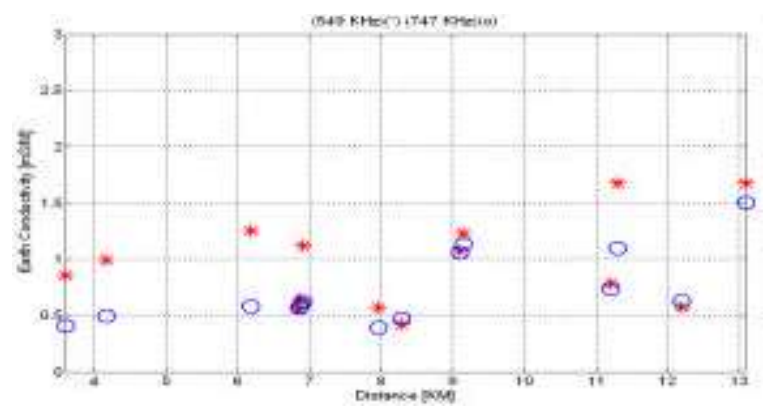

Fig. 12: $\mathrm{GC}(\mathrm{mS} / \mathrm{M})$ vs distance (KM) (ITU ref. 10 $\mathrm{mS} / \mathrm{M})$

interpolation are as follows. Then GC is determined based on tables and curves presented [3] from near points assuming the ground around the transmitter as homogenous and determining distant points conductivity based on information of previous points, considering the necessity to use Millington's algorithm in points where there is unusual variation of electric field. Of course, GC's staircase variation should be considered too (the above assumption would be problematic regarding the slow variation of GC). The significant points of this method: (1)-Accuracy in transmitter's important and temporary quantities (transmitter power, antenna gain, antenna and transmitter matching, feeder and antenna system efficiency etc.). (2)-Ground elements existing between the transmitter and the observation point (civil pointsrough ground, vegetation cover, etc.) which will be effective in received field.

The information used in this method were applied to transmitter's related to Table 2 (two frequency transmitter) and 3 (Fig. 12 and 13). The conductivity rate has been drawn regarding distance assuming the homogeneity of the area (which is relatively accurate).

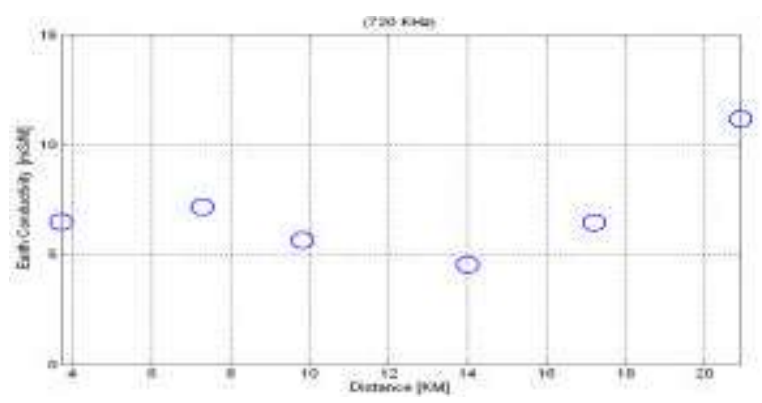

Fig. 13: GC (mS/M) vs distance (KM) (ITU ref. $\mathrm{mS} / \mathrm{M})$

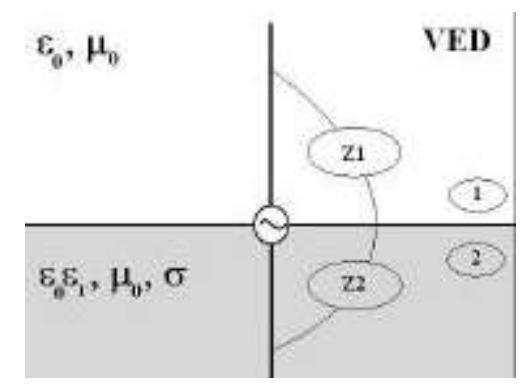

Fig. 14: Vertical Electric Dipole on the ground

It is observed that going far from the transmitter the method variation (error) increases. The outstanding point is that $\mathrm{GC}$ is not the same in two frequencies which were not mentioned before and else that the above obtained information do not conform to the previous method and is not compatible with the resources' information regarding GC. The obtained GC in Sirjaan plateau is about $0.5-1 \mathrm{mS} / \mathrm{M}$ which is about $10 \mathrm{mS} / \mathrm{M}$ in recommendations and it is about $5-7 \mathrm{mS} / \mathrm{M}$ in Maahidasht plateau which is introduced $3 \mathrm{mS} / \mathrm{M}$ in recommendation.

The new method to measure conductivity: In the new method GC is determined based on determining HED antenna impedance near the ground in a way that comparison of antenna impedance in free space and near the ground will provide a criterion to determine GC. To determine GC use is made of an antenna wire which is located near the ground. The antenna impedance variation to antenna impedance in free space is the criterion to determine GC. In the first case the antenna was considered Vertical Electric Dipole (VED) which is the common structure used in radio transmitters and the antenna impedance are influenced by two half spaces (the free space and the ground).It can be hypothesized that antenna impedance includes free half space impedance in series with media half space (ground with attenuation) impedance (due to the monopoles in a separate half space) Fig. 14. 


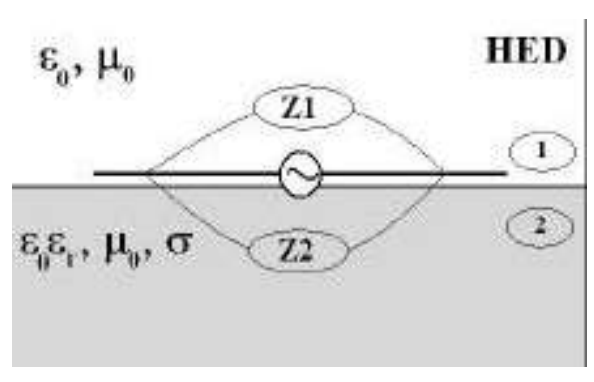

Fig. 15: Horizontal electric dipole

But as a result of a low impedance obtained from half space 2 in opposition to free space 1 (two impedance series) the GC variation will have a low effect on antenna impedance.

Practically, in radio transmitter to decrease earth effect on antenna impedance and increase radiation power a wire network is set under the antenna so that with increase of conductivity.

In the second case, the antenna is assumed in the form of HED near the (electric isolated) ground, thus two monopoles (covered wire) are set on the ground (with a fixed distance). In this case, there are also two half spaces around the antenna, the dipole is at the edge of each one. Contrary to the previous case, the impedances influenced by the two medias act parallel and due to the small value of media 2 impedance, the GC effect on antenna impedance is great and observable. To determine horizontal antenna impedance near the ground, it is necessary to determine electric field around antenna Fig. 15.

Determining electric field by Mie method: At first, it is reminded to determine the GC with the considered electric characteristics (flat earth along with horizontal antenna, in general solving the not so simple Sommerfeld's integral) the horizontal antenna is set near the surface of the dielectric sphere with attenuation $(\varepsilon, \sigma)$ of big radius. If the sphere radius is big enough, the answer to the two problems will be the same. The difference is that solving the problem with the second case is simpler. G. Mie presented a solution to wave propagation in spherical coordinate in 1908. The electric incident and reflection field (from sphere) resulted from hertz dipole antenna with $I$ current, $\Delta l$ length and ad orientation in $(r 0, \theta 0, \varphi 0)$ point near dielectric sphere with $a$ radius and electric characteristics $(\varepsilon r, \sigma)$ in $a<r<r 0$ area are obtained using the relations below (Appendix A).

$$
\mathbf{E}^{\mathrm{i}}=\sum_{\mathrm{n}=1}^{\infty} \sum_{\mathrm{m}=-\mathrm{n}}^{\mathrm{m}=\mathrm{n}}\left(\mathrm{A}_{\mathrm{mn}}^{(4)} \mathrm{M}_{\mathrm{mn}}^{1}(\mathrm{r}, \theta, \phi)+\mathrm{B}_{\mathrm{mn}}^{(4)} \mathrm{N}_{\mathrm{mn}}^{1}(\mathrm{r}, \theta, \phi)\right)
$$

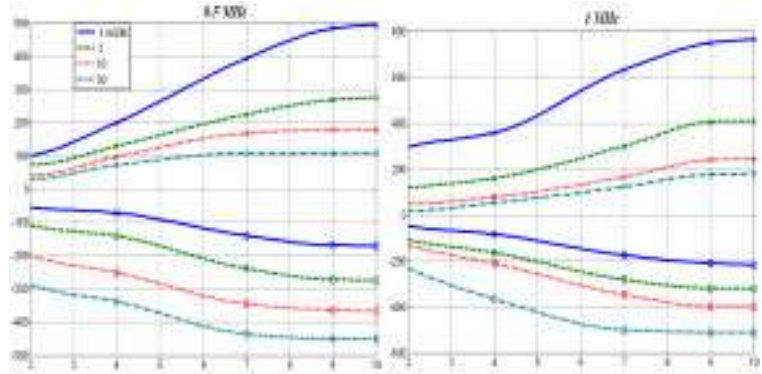

Fig. 16: Zin vs Sph. Radius (real(x) $\operatorname{imag}(\mathrm{o}))$

$$
\mathbf{E}^{\mathrm{S}}=\sum_{\mathrm{n}=1}^{\infty} \sum_{\mathrm{m}=-\mathrm{n}}^{\mathrm{m}=\mathrm{n}}\left(\mathrm{A}_{\mathrm{mn}}^{\mathrm{S}} \mathrm{M}_{\mathrm{mn}}^{4}(\mathrm{r}, \theta, \phi)+\mathrm{B}_{\mathrm{mn}}^{\mathrm{S}} \mathrm{N}_{\mathrm{mn}}^{4}(\mathrm{r}, \theta, \phi)\right)
$$

HED simulation: The horizontal antenna near the ground was simulated with much smaller horizontal electric currents of to convert the relations above to an applicable mode $\Delta l \approx 0.01 \lambda$ wave length. To equalize the figure above with the HED problem, also, the sphere radius was considered $a=5-10 \lambda$. The half wave dipole antenna including two monopoles (a quarter of the wave) was located near the sphere (e.g. sphere radius $7 \lambda$, each monopole length $0.25 \lambda 7 \lambda=0.0357 \mathrm{rad}=2.05^{\circ}$ which shows the problem's proper accuracy in flat earth approximation).Antenna is located in $a \varphi$ orientation on $z=0$ plate with $x$ axis centrality or in $a \theta$ orientation on $y=0$ plate with $x$ axis centrality or any figure with symmetrical state if the antenna distance from the sphere is small enough, $d<(\lambda 500)$, the antenna can be considered parallel to the surface. The antenna distance (d) from the surface is about $3 \mathrm{~mm}$. After determining electric field with $E i$ incident and $E s$ scattering parts, antenna impedance includes inherent impedance $Z i$ ) and the mutual impedance $(Z s)$. The $\lambda / 2$ dipole inherent impedance value is equal to $Z i=72+j 46 \Omega$ which can be computed and known for other antenna lengths. The $Z s$ varying the antenna impedance and dependent upon GC is obtained from computations (computing the Es alone is simpler and involves no problem to clear any vagueness). In this case antenna impedance is equal to:

$$
\begin{aligned}
& Z_{\text {in }}=-\frac{1}{I_{m}^{2}} \int_{-\lambda / 4}^{\lambda / 4} I_{\text {ant }} E_{\text {ant }}^{\mathrm{t}} \cdot d l, E_{\text {ant }}^{\mathrm{t}}=E_{\text {ant }}^{\mathrm{i}}+\mathrm{E}_{\text {ant }}^{\mathrm{s}} \\
& Z_{\text {in }}=72+\mathrm{j} 46-\frac{1}{\mathrm{I}_{\mathrm{m}}^{2}} \int_{-\lambda / 4}^{\lambda / 4} \mathrm{I}_{\text {ant }} \mathrm{E}_{\text {ant }}^{\mathrm{s}} \cdot \mathrm{dl}
\end{aligned}
$$

In Fig. 16, antenna impedance is drawn in different conductivities for two frequencies based on the 
Table 5: HED Antenna impedance $(\mathrm{R}+\mathrm{j} \mathrm{X})$

\begin{tabular}{|c|c|c|c|c|}
\hline \multirow{2}{*}{$\begin{array}{l}\sigma \\
(\mathrm{S} / \mathrm{M})\end{array}$} & \multicolumn{4}{|c|}{ Frequency $(\mathrm{MHz})$} \\
\hline & 0.5 & 0.75 & 1 & 1.5 \\
\hline$\overline{0.001}$ & $493-$ j 170 & $630-\mathrm{j} 195$ & $765-j 218$ & $985-j 234$ \\
\hline 0.002 & $358-\mathrm{j} 231$ & $449-\mathrm{j} 260$ & $545-\mathrm{j} 279$ & $713-\mathrm{j} 299$ \\
\hline 0.003 & $274-\mathrm{j} 274$ & $335-\mathrm{j} 304$ & $408-\mathrm{j} 320$ & $541-\mathrm{j} 342$ \\
\hline 0.004 & $249-\mathrm{j} 296$ & $300-\mathrm{j} 324$ & $365-\mathrm{j} 339$ & $482-\mathrm{j} 360$ \\
\hline 0.006 & $214-\mathrm{j} 328$ & $252-\mathrm{j} 351$ & $303-\mathrm{j} 365$ & $397-\mathrm{j} 384$ \\
\hline 0.008 & $193-\mathrm{j} 350$ & $222-\mathrm{j} 370$ & $266-\mathrm{j} 382$ & $345-\mathrm{j} 400$ \\
\hline 0.010 & $178-\mathrm{j} 367$ & $204-\mathrm{j} 385$ & $244-\mathrm{j} 398$ & $317-j 416$ \\
\hline 0.014 & $154-\mathrm{j} 393$ & $177-\mathrm{j} 413$ & $215-\mathrm{j} 429$ & $281-\mathrm{j} 449$ \\
\hline 0.018 & $137-\mathrm{j} 411$ & $160-\mathrm{j} 435$ & $197-\mathrm{j} 455$ & $261-\mathrm{j} 478$ \\
\hline 0.022 & $124-\mathrm{j} 427$ & $148-\mathrm{j} 454$ & $188-\mathrm{j} 477$ & $253-\mathrm{j} 503$ \\
\hline 0.026 & $114-\mathrm{j} 440$ & $139-\mathrm{j} 470$ & $181-\mathrm{j} 496$ & $248-\mathrm{j} 525$ \\
\hline 0.030 & $108-\mathrm{j} 450$ & $135-\mathrm{j} 483$ & $178-\mathrm{j} 512$ & $246-j 543$ \\
\hline
\end{tabular}

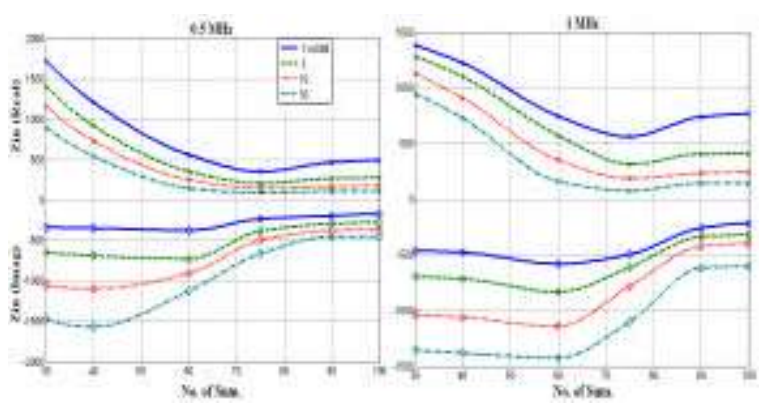

Fig. 17: Zin vs No. of Sum (real (x) image (o))
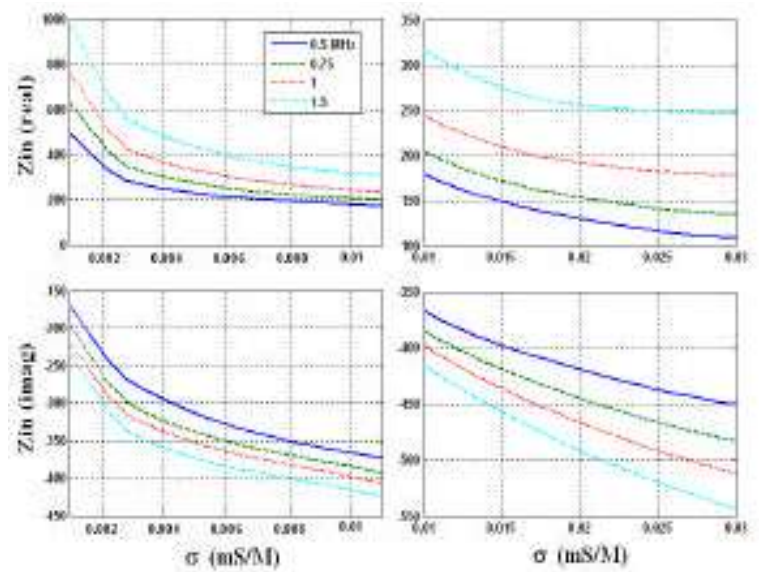

Fig. 18: Ipedance based on conduct (S/M)

dielectric sphere radius (100 constant addition numbers instead of infinity).

In Fig. 17, antenna impedance is drawn for two frequencies in different conductivities based on number of addition (constant dielectric sphere radius $a=10 \lambda$ ).

Increase in impedance results in decrease of real and imaginary value of the antenna; in general convergence is higher in the real part. Considering figures $10 \lambda$ radius and 100 addition number suffices convergence (in extremely specific grounds $\sigma \leq 0.0003$ $S / M$ radius and addition number should be higher which of course are very rare).

In Fig. 18 horizontal antenna impedance is drawn based on GC in different frequencies using Mie method.

A criterion of the (average) area conductivity is obtained measuring antenna impedance in several points (pilot) in the considered area and determining GC based on curves or tables. To ease the use of them, (as recommendation) previous curves are introduced as Table 5 .

What should be mentioned before discussing the measurement results is that as a result of layered structure of GC, frequency is not the same through the band. Soil humidity is increased with increase of depth leading to higher conductivity. Therefore the average conductivity is influenced by depth and in this way impedance is dependent upon frequency. Due to this fact measurement was done in three frequencies $(0.75$, 1 , $1.5 \mathrm{MHz}$ ), but in recommendation conductivity is defined constant in frequency band.

\section{MEASUREMENT RESULTS}

The plain and rocky mountains slope of Kermaanshaah area (Table 4) were chosen as the practical example. It is reminded that the plain conductivity was several times higher that the mountain slope and the mountain slope measurements are closer to introduced conductivity in recommendation. Measuring was done in 3 frequencies $0.75,1,1.5 \mathrm{MHz}$ (each monopole's length 100, 75, $50 \mathrm{M}$ ). To determine the impedance the below antenna measurement set was used:

- $\quad$ Signal Generator RG-4 (Delta Electronics).

- RF BRIDGE 1606B (General Radio Company).

- FS Meter FIM-41 (Potomac Instruments Inc.).

Two wires are set in one direction like a dipole. To increase accuracy, antenna average impedance was measured in two measurements perpendicularly (on the ground). Measurements were done after the last spring rain (May-31-2007) with a gap of seven days. There was no rain during measurement which could change the ground electric characteristic. Fig. 19 shows area's measurement points.

Table 6 shows the impedance and related conductivity in three frequencies. Dependence of the conductivity upon the frequency was higher in plain 
Table 6: Conductivity at points A and B (mS/M)

\begin{tabular}{lcccc}
\hline $\begin{array}{l}\text { Points and } \\
\text { Freq. (MHz) }\end{array}$ & & Week 1 & Week 2 & $\begin{array}{l}\text { Week 3 } \\
\text { Jay 31 }\end{array}$ \\
\hline A & 0.75 & 8.6 & 8.2 & 7.8 \\
& 1.00 & 7.7 & 7.2 & 6.4 \\
& 1.50 & 6.2 & 5.6 & 5.0 \\
\hline B & 0.75 & 27.1 & 26.3 & 24.4 \\
& 1.00 & 24.3 & 23.1 & 20.8 \\
& 1.50 & 22.4 & 19.2 & 16.6 \\
\hline
\end{tabular}

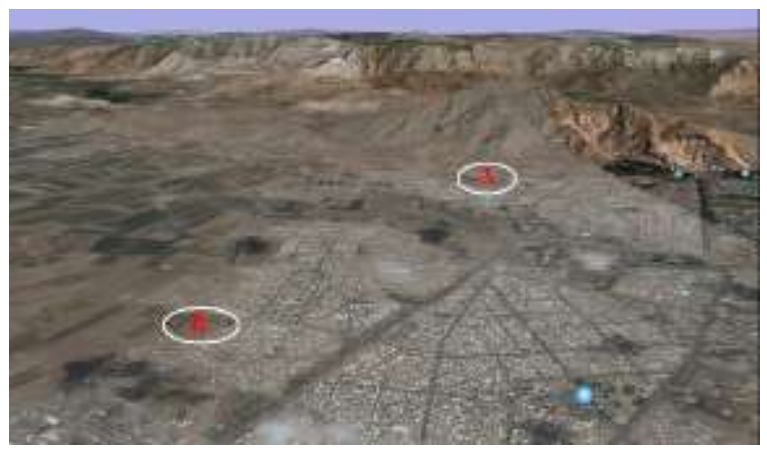

Fig. 19: Measurement points

that in mountain slope and the reason was that clay kept more humidity. Since the distance of the wire from the ground was changed (several millimeters), the illusive value was less accurate; however, one can consider the conductivity as the two values' average.

\section{CONCLUSION AND SUGGESTIONS}

Use of the aforementioned nethod to determine pilot points GC in the considered area and after that two dimensional interpolations can determine the area conductivity model. In the above method the attenuation influences of crossing rough earth are not predictable.

Through measurement it was observed for dipole near wave length the impedance real part is minimum and of the same amount imaginary part is (near) the zero. Determining the above mentioned values and considering antenna's VSWR also can be a new method to measure GC in specific frequency. In addition changes in conductivity resulting from rain and season changes can be the subject of further considerations.

In digital broadcasting structure, the minimum receivable field and difference of the same channel transmitters' surface is lower than that of analogue broadcasting to prevent intervention [13]. Besides, it requires higher accuracy of the GC atlas than the present condition to be able to create one frequency channels and to control cover area by the transmitter's power.

\section{ACKNOWLEDGMENT}

Thanks to Mr. Ali Asgari deputy of IRIB technical, Mr. Esmaeeli and Mr. Nazari director-general of radio transmitters, Mr. Pahlavani head of research center of radio transmitters for made coordination required for execution of the project.

\section{Appendix A}

Solving the Scalar wave equation in spherical coordinates leads to the below equation [14].

$$
\Psi_{m n}^{\mathrm{g}}(\mathrm{r}, \theta, \phi)=\sum_{\mathrm{n}=0}^{\infty} \sum_{\mathrm{m}=-\mathrm{n}}^{\mathrm{n}} \mathrm{A}_{\mathrm{mn}}^{\mathrm{g}} \mathrm{z}_{\mathrm{n}}^{(\mathrm{g})}(\mathrm{kr}) \mathrm{P}_{\mathrm{n}}^{|\mathrm{m}|}(\cos \theta) \mathrm{e}^{\mathrm{jm} \phi}
$$

If we define (M)TE and $(N) T M$ modes as such:

$$
\begin{aligned}
& \mathrm{M}=\nabla \times\left(\mathrm{ra}_{\mathrm{r}} \Psi\right) \\
& \mathrm{N}=\frac{1}{\mathrm{k}} \nabla \times(\mathrm{M})
\end{aligned}
$$

Each one will satisfy the vector wave equation in the spherical coordinates.

$$
\begin{aligned}
& \nabla \times \nabla \times\left(\begin{array}{l}
\mathrm{M} \\
\mathrm{N}
\end{array}\right)+\mathrm{k}^{2}\left(\begin{array}{l}
\mathrm{M} \\
\mathrm{N}
\end{array}\right)=0 \\
& \nabla \cdot\left(\begin{array}{l}
\mathrm{M} \\
\mathrm{N}
\end{array}\right)=0
\end{aligned}
$$

In this way (the orthogonal characteristics of the modes to each other) the electric and magnetic fields become

$$
\begin{aligned}
& \mathbf{E}=\sum_{\mathrm{n}=1}^{\infty} \sum_{\mathrm{m}=-\mathrm{n}}^{\mathrm{m}=\mathrm{n}}\left(\mathrm{A}_{\mathrm{mn}} \mathrm{M}_{\mathrm{mn}}^{\mathrm{g}}(\mathrm{r}, \theta, \phi)+\mathrm{B}_{\mathrm{mn}} \mathrm{N}_{\mathrm{mn}}^{\mathrm{g}}(\mathrm{r}, \theta, \phi)\right) \\
& \mathbf{H}=\frac{\mathrm{j}}{\eta_{0}} \sum_{\mathrm{n}=1}^{\infty} \sum_{\mathrm{m}=-\mathrm{n}}^{\mathrm{m}=\mathrm{n}}\left(\mathrm{A}_{\mathrm{mn}} \mathrm{M}_{\mathrm{mn}}^{\mathrm{g}}(\mathrm{r}, \theta, \phi)+\mathrm{B}_{\mathrm{mn}} \mathrm{N}_{\mathrm{mn}}^{\mathrm{g}}(\mathrm{r}, \theta, \phi)\right)
\end{aligned}
$$

In which $M$ and $N$ are in

$$
\begin{aligned}
& M_{\mathrm{mn}}^{(1),(4)}(\mathrm{r}, \theta, \phi)=\mathrm{M}_{\mathrm{mnr}}^{(1),(4)} \hat{\mathrm{a}}_{\mathrm{r}}+\mathrm{M}_{\mathrm{mn} \theta}^{(1),(4)} \hat{\mathrm{a}}_{\theta}+\mathrm{M}_{\mathrm{mn} \phi}^{(1),(4)} \hat{\mathrm{a}}_{\phi} \\
& \mathrm{N}_{\mathrm{mn}}^{(1),(4)}(\mathrm{r}, \theta, \phi)=\mathrm{N}_{\mathrm{mnr}}^{(1),(4)} \hat{\mathrm{a}}_{\mathrm{r}}+\mathrm{N}_{\mathrm{mn} \theta}^{(1),(4)} \hat{\mathrm{a}}_{\theta}+\mathrm{N}_{\mathrm{mn} \phi}^{(1),(4)} \hat{\mathrm{a}}_{\phi} \\
& \mathrm{M}_{\mathrm{mnr}}^{(1),(4)}=0 \\
& \mathrm{M}_{\mathrm{mn} \theta}^{(1),(4)}=\frac{\mathrm{jm}}{\sin \theta} \mathrm{P}_{\mathrm{n}}^{|\mathrm{m}|}(\cos \theta) \mathrm{z}_{\mathrm{n}}^{(1),(4)}(\mathrm{kr}) \mathrm{e}^{\mathrm{jm} \phi} \\
& \mathrm{M}_{\mathrm{mn} \phi}^{(1),(4)}=-\frac{\mathrm{d}}{\mathrm{d} \theta} \mathrm{P}_{\mathrm{n}}^{|\mathrm{m}|}(\cos \theta) \mathrm{z}_{\mathrm{n}}^{(1),(4)}(\mathrm{kr}) \mathrm{e}^{\mathrm{jm} \phi}
\end{aligned}
$$




$$
\begin{aligned}
& \mathrm{N}_{\mathrm{mnr}}^{(1),(4)}=\frac{\mathrm{n}(\mathrm{n}+1)}{\mathrm{kr}} \mathrm{P}_{\mathrm{n}}^{|\mathrm{m}|}(\cos \theta) \mathrm{z}_{\mathrm{n}}^{(1),(4)}(\mathrm{kr}) \mathrm{e}^{\mathrm{jm} \phi} \\
& \mathrm{N}_{\mathrm{mn} \theta}^{(1),(4)}=\frac{\mathrm{d}}{\mathrm{d} \theta} \mathrm{P}_{\mathrm{n}}^{|\mathrm{m}|}(\cos \theta) \frac{1}{\mathrm{kr} d \mathrm{~d}}\left[\mathrm{rz}_{\mathrm{n}}^{(1),(4)}(\mathrm{kr})\right] \mathrm{e}^{\mathrm{jm} \phi} \\
& \mathrm{N}_{\mathrm{mn} \phi}^{(1),(4)}=-\frac{\mathrm{jm}}{\sin \theta} \mathrm{P}_{\mathrm{n}}^{|\mathrm{m}|}(\cos \theta) \frac{1}{\mathrm{kr}} \frac{\mathrm{d}}{\mathrm{dr}}\left[\mathrm{rz}_{\mathrm{n}}^{(1),(4)}(\mathrm{kr})\right] \mathrm{e}^{\mathrm{jm} \phi} \\
& \mathrm{z}_{\mathrm{n}}^{1}(\mathrm{x})=\mathrm{j}_{\mathrm{n}}(\mathrm{x}), \quad \mathrm{j}_{\mathrm{n}}(\mathrm{x})=\sqrt{\frac{\pi}{2 \mathrm{x}}} \mathrm{J}_{\mathrm{n}+\frac{1}{2}}(\mathrm{x}) \\
& \mathrm{z}_{\mathrm{n}}^{4}(\mathrm{x})=\mathrm{h}_{\mathrm{n}}^{(2)}(\mathrm{x}), \quad \mathrm{h}_{\mathrm{n}}^{(2)}(\mathrm{x})=\sqrt{\frac{\pi}{2 \mathrm{x}}} \mathrm{H}_{\mathrm{n}+\frac{1}{2}}(\mathrm{x})
\end{aligned}
$$

Here $\mathrm{j}_{\mathrm{n}}(\mathrm{x}), \mathrm{h}_{\mathrm{n}}^{2}(\mathrm{x}), \mathrm{j}^{\prime}{ }_{\mathrm{n}}(\mathrm{x}), \mathrm{h}_{\mathrm{n}}^{2}{ }^{\prime}(\mathrm{x})$, are spherical Bessel function and related derivatives. Considering the existence of current element (hertz dipole) out of the sphere on $(r o, \theta o, \varphi o)$ point with $I$ current and $\Delta l$ length and $a d$ direction, then

$$
\mathrm{P}_{0}=\mathrm{p}_{0} \hat{\mathrm{a}}_{\mathrm{d}}, \quad \mathrm{p}_{0}=\frac{I \Delta 1}{\mathrm{j} \omega}
$$

The field in $r<r o$ is like

$$
\begin{aligned}
& \mathbf{E}=\sum_{\mathrm{n}=1}^{\infty} \sum_{\mathrm{m}=-\mathrm{n}}^{\mathrm{m}=\mathrm{n}}\left(\mathrm{A}_{\mathrm{mn}}^{(4)} \mathrm{M}_{\mathrm{mn}}^{1}(\mathrm{r}, \theta, \phi)+\mathrm{B}_{\mathrm{mn}}^{(4)} \mathrm{N}_{\mathrm{mn}}^{1}(\mathrm{r}, \theta, \phi)\right) \\
& \mathbf{H}=\frac{\mathrm{j}}{\eta_{0}} \sum_{\mathrm{n}=1}^{\infty} \sum_{\mathrm{m}=-\mathrm{n}}^{\mathrm{m}=\mathrm{n}}\left(\mathrm{A}_{\mathrm{mn}}^{(4)} \mathrm{M}_{\mathrm{mn}}^{1}(\mathrm{r}, \theta, \phi)+\mathrm{B}_{\mathrm{mn}}^{(4)} \mathrm{N}_{\mathrm{mn}}^{1}(\mathrm{r}, \theta, \phi)\right)
\end{aligned}
$$

And for $r>r o$ is like

$$
\begin{aligned}
& \mathbf{E}=\sum_{\mathrm{n}=1}^{\infty} \sum_{\mathrm{m}=-\mathrm{n}}^{\mathrm{m}=\mathrm{n}}\left(\mathrm{A}_{\mathrm{mn}}^{(1)} \mathrm{M}_{\mathrm{mn}}^{4}(\mathrm{r}, \theta, \phi)+\mathrm{B}_{\mathrm{mn}}^{(1)} \mathrm{N}_{\mathrm{mn}}^{4}(\mathrm{r}, \theta, \phi)\right) \\
& \mathbf{H}=\frac{\mathrm{j}}{\eta_{0}} \sum_{\mathrm{n}=1}^{\infty} \sum_{\mathrm{m}=-\mathrm{n}}^{\mathrm{m}=\mathrm{n}}\left(\mathrm{A}_{\mathrm{mn}}^{(1)} \mathrm{M}_{\mathrm{mn}}^{4}(\mathrm{r}, \theta, \phi)+\mathrm{B}_{\mathrm{mn}}^{(1)} \mathrm{N}_{\mathrm{mn}}^{4}(\mathrm{r}, \theta, \phi)\right)
\end{aligned}
$$

In which the coefficients $\mathrm{A}^{(1,4)}, \mathrm{B}^{(1,4)}$ are like

$$
\begin{aligned}
& \mathrm{A}_{\mathrm{mn}}^{(1),(4)}=\left(\frac{-\mathrm{jk}_{1}^{3} \mathrm{p}_{0}}{4 \pi \varepsilon}\right) \frac{(\mathrm{n}-|\mathrm{m}|) !}{(\mathrm{n}+|\mathrm{m}|) ! \mathrm{n}(\mathrm{n}+1)} \hat{a}_{\mathrm{d}} \cdot \mathrm{M}_{-\mathrm{mn}}^{(1),(4)}\left(\mathrm{r}_{0}, \theta_{0}, \phi_{0}\right) \\
& \mathrm{B}_{\mathrm{mn}}^{(1),(4)}=\left(\frac{-\mathrm{jk}{ }_{1}^{3} \mathrm{p}_{0}}{4 \pi \varepsilon}\right) \frac{(\mathrm{n}-|\mathrm{m}|) !}{(\mathrm{n}+|\mathrm{m}|) ! \mathrm{n}(\mathrm{n}+1)} \hat{a}_{\mathrm{d}} \cdot \mathrm{N}_{-\mathrm{mn}}^{(1),(4)}\left(\mathrm{r}_{0}, \theta_{0}, \phi_{0}\right)
\end{aligned}
$$

Which shows application of boundary conditions in $r=$ ro. Now according to the equations, if dielectric sphere of $a$ radius, $\varepsilon r$ insulation coefficient and $\sigma$ conductivity are located in center in a way that the source is out of the sphere $a<r o$ for $a<r<r o$ area of the radiation field is obtained from the below relations:

$$
\begin{aligned}
& \mathbf{E}^{\mathrm{i}}=\sum_{\mathrm{n}=1}^{\infty} \sum_{\mathrm{m}=-\mathrm{n}}^{\mathrm{m}=\mathrm{n}}\left(\mathrm{A}_{\mathrm{mn}}^{(4)} \mathrm{M}_{\mathrm{mn}}^{1}(\mathrm{r}, \theta, \phi)+\mathrm{B}_{\mathrm{mn}}^{(4)} \mathrm{N}_{\mathrm{mn}}^{1}(\mathrm{r}, \theta, \phi)\right) \\
& \mathbf{H}^{\mathrm{i}}=\frac{\mathrm{j}}{\eta_{0}} \sum_{\mathrm{n}=1}^{\infty} \sum_{\mathrm{m}=-\mathrm{n}}^{\mathrm{m}=\mathrm{n}}\left(\mathrm{A}_{\mathrm{mn}}^{(4)} \mathrm{M}_{\mathrm{mn}}^{1}(\mathrm{r}, \theta, \phi)+\mathrm{B}_{\mathrm{mn}}^{(4)} \mathrm{N}_{\mathrm{mn}}^{1}(\mathrm{r}, \theta, \phi)\right)
\end{aligned}
$$

And the reflected field of the dielectric sphere is obtained according to the relations below.

$$
\begin{aligned}
& \mathbf{E}^{\mathrm{S}}=\sum_{\mathrm{n}=1}^{\infty} \sum_{\mathrm{m}=-\mathrm{n}}^{\mathrm{m}=\mathrm{n}}\left(\mathrm{A}_{\mathrm{mn}}^{\mathrm{S}} \mathrm{M}_{\mathrm{mn}}^{4}(\mathrm{r}, \theta, \phi)+\mathrm{B}_{\mathrm{mn}}^{\mathrm{S}} \mathrm{N}_{\mathrm{mn}}^{4}(\mathrm{r}, \theta, \phi)\right) \\
& \mathbf{H}^{\mathrm{S}}=\frac{\mathrm{j}}{\eta_{0}} \sum_{\mathrm{n}=1}^{\infty} \sum_{\mathrm{m}=-\mathrm{n}}^{\mathrm{m}=\mathrm{n}}\left(\mathrm{A}_{\mathrm{mn}}^{\mathrm{S}} \mathrm{M}_{\mathrm{mn}}^{4}(\mathrm{r}, \theta, \phi)+\mathrm{B}_{\mathrm{mn}}^{\mathrm{S}} \mathrm{N}_{\mathrm{mn}}^{4}(\mathrm{r}, \theta, \phi)\right)
\end{aligned}
$$

Applying the boundary conditions to the sphere surface to make the tangential radiation $E i$ and reflected fields $E s$ with $E t$ crossing the $\mathrm{B}_{\mathrm{mn}}^{\mathrm{S}}, \mathrm{A}_{\mathrm{mn}}^{\mathrm{S}}$ coefficients are obtained as below

$$
\begin{aligned}
& \mathrm{A}_{\mathrm{mn}}^{\mathrm{S}}=\frac{\frac{\mu_{2}}{\mu_{1}} \hat{\mathrm{J}}_{\mathrm{n}}^{\prime}\left(\rho_{1}\right) \mathrm{j}_{\mathrm{n}}\left(\rho_{2}\right)-\mathrm{j}_{\mathrm{n}}\left(\rho_{1}\right) \hat{\mathrm{J}}_{\mathrm{n}}^{\prime}\left(\rho_{2}\right)}{\mathrm{h}_{\mathrm{n}}^{(2)}\left(\rho_{1}\right) \hat{J}_{\mathrm{n}}^{\prime}\left(\rho_{2}\right)-\frac{\mu_{1}}{\mu_{2}} \hat{H}_{\mathrm{n}}^{\prime(2)}\left(\rho_{1}\right) \mathrm{j}_{\mathrm{n}}\left(\rho_{2}\right)} \mathrm{A}_{\mathrm{mn}}^{4} \\
& \mathrm{~B}_{\mathrm{mn}}^{\mathrm{S}}=\frac{\frac{\mu_{2}}{\mu_{1}}\left(\frac{\mathrm{k}_{2}}{\mathrm{k}_{1}}\right)^{2} \hat{J}_{\mathrm{n}}^{\prime}\left(\rho_{1}\right) \mathrm{j}_{\mathrm{n}}\left(\rho_{2}\right)-\mathrm{j}_{\mathrm{n}}\left(\rho_{1}\right) \hat{J}_{\mathrm{n}}^{\prime}\left(\rho_{2}\right)}{\mathrm{h}_{\mathrm{n}}^{(2)}\left(\rho_{1}\right) \hat{J}_{\mathrm{n}}^{\prime}\left(\rho_{2}\right)-\frac{\mu_{1}}{\mu_{2}}\left(\frac{\mathrm{k}_{2}}{\mathrm{k}_{1}}\right)^{2} \hat{H}_{\mathrm{n}}^{\prime(2)}\left(\rho_{1}\right) \mathrm{j}_{\mathrm{n}}\left(\rho_{2}\right)} \mathrm{B}_{\mathrm{mn}}^{4}
\end{aligned}
$$

In which

$$
\begin{aligned}
& \rho_{1}=k_{1} \mathrm{a}, \quad \mathrm{k}_{1}=\omega \sqrt{\mu_{0} \varepsilon_{0}} \\
& \rho_{2}=\mathrm{k}_{2} \mathrm{a}, \quad \mathrm{k}_{2}=\omega \sqrt{\mu_{0} \varepsilon_{2}}, \quad \varepsilon_{2}=\varepsilon_{0}\left(\varepsilon_{\mathrm{r} 2}-\frac{\mathrm{j} \sigma_{2}}{\omega \varepsilon_{0}}\right)
\end{aligned}
$$

In this relation $\varepsilon_{2}$ is complex and $\hat{\mathrm{H}}_{\mathrm{n}}^{(2)}(\mathrm{x}), \hat{\mathrm{J}}_{\mathrm{n}}^{\prime}(\mathrm{x})$ is the related Ricotti Bessel function.

$$
\begin{aligned}
& \hat{\mathrm{J}}_{\mathrm{n}}{ }^{\prime}(\mathrm{x})=\frac{\mathrm{d}}{\mathrm{dx}}\left(\sqrt{\frac{\pi \mathrm{x}}{2}} \mathrm{~J}_{\mathrm{n}+\frac{1}{2}}(\mathrm{x})\right)=\mathrm{j}_{\mathrm{n}}(\mathrm{x})+\mathrm{x} \mathrm{j}_{\mathrm{n}}^{\prime}(\mathrm{x}) \\
& \hat{\mathrm{H}}_{\mathrm{n}}^{\prime(2)}(\mathrm{x})=\frac{\mathrm{d}}{\mathrm{dx}}\left(\sqrt{\frac{\pi \mathrm{x}}{2}} \mathrm{H}_{\mathrm{n}+\frac{1}{2}}^{(2)}(\mathrm{x})\right)=\mathrm{h}_{\mathrm{n}}^{(2)}(\mathrm{x})+\mathrm{x} \mathrm{h} \underset{\mathrm{n}}{\mathrm{\prime}(2)}(\mathrm{x})
\end{aligned}
$$




\section{REFERENCES}

1. International Telecommunication Union (ITU) Recommendations. Characteristics of AM sound broadcasting reference receivers for planning purposes. REC. ITU-R BS 703.

2. International Telecommunication Union (ITU) Recommendations. World atlas of Ground Conductivities. REC. ITU-R P 832-1.

3. International Telecommunication Union (ITU) Recommendations. Ground-wave propagation curves for frequencies between $10 \mathrm{kHz}$ and 30 MHz. REC. ITU-R P 368-7.

4. Zenneck, J., 1907. Propagation of plane EM Waves Along a Plane Conducting Surface. Ann. Phys. (Leipzig), 23: 846-866.

5. Sommerfeld, A.N., 1926. Propagation of Waves in Wireless Telgraphy. Ann. Phys. (Leipzig), 81: 1135-1153.

6. Norton, K.A., 1936. The propagation of radio waves Over the Surface of the Earth. Proceedings of the IRE, 24: 1367-1387, 25: 1203-1236.

7. Wait, J.R., 1953. Radiation From a vertical Electric Dipole Over a Stratified ground. IRE transaction on Antenna and propagation, AP-1, pp: 9-12; AP-2: 144-146.
8. King, R.W.P. and Jr.C. Harrison, 1998. Electromagnetic Ground-Wave Field of Vertical Antennas for Communication at 1 to $30 \mathrm{MHz}$. IEEE Trans. on Electromagnetic Compatibility, Vol: 40 .

9. Collin, R.E., 2004. Hertzian Dipole Radiating Over A Lossy Earth or Sea: Some Early and Late $20^{\text {th }}$ century Controversies. IEEE Antenna and Propagation Magazine, Vol: 46.

10. Millington, G., 1949. Groundwave Propagation Over an Inhomogeneous Smooth Earth. Proceedings of the IEE (UK), Pt. III, pp: 53-64.

11. Vahab, S., A. Makki and Farzad Pahlavani, 2006. Evaluation effect of changing ground conductivity for field strength in MW Band. $1^{\text {st }}$ Broadcast Engineering Conference August, IRIB Faculty, Tehran, Iran.

12. Wenner, F., 1915. A Method of Measuring Earth Receptivity. Report No. Bulletin of Bureau of Standards, Vol: 12.

13. International Telecommunication Union (ITU) Recommendations. Planning parameters for digital broadcasting at frequencies below $30 \mathrm{MHz}$. REC. ITU-BS1615.

14. Jones, D.S., 1964. The theory of Electromagnetism, Pergamon Press, Oxford. 